\title{
Effective Treatment of Chronic Low Back Pain in Humans Reverses Abnormal Brain Anatomy and Function
}

\author{
David A. Seminowicz, ${ }^{1,2,3}$ Timothy H. Wideman, ${ }^{1,7,8}$ Lina Naso, ${ }^{1,2,3}$ Zeinab Hatami-Khoroushahi, ${ }^{1,2,3}$ \\ Summaya Fallatah, ${ }^{4,8}$ Mark A. Ware, ${ }^{1,8}$ Peter Jarzem, ${ }^{2,9}$ M. Catherine Bushnell, ${ }^{1,3,4,6}$ Yoram Shir, ${ }^{1,8}$ Jean A. Ouellet, ${ }^{2,9}$ \\ and Laura S. Stone ${ }^{1,2,3,4,5,6}$ \\ ${ }^{1}$ Alan Edwards Centre for Research on Pain, ${ }^{2}$ McGill Scoliosis and Spine Research Group, ${ }^{3}$ Faculty of Dentistry, Departments of ${ }^{4}$ Anesthesiology, \\ ${ }^{5}$ Pharmacology and Therapeutics, and ${ }^{6}$ Neurology and Neurosurgery, Faculty of Medicine, and ${ }^{7}$ Department of Psychology, Faculty of Science, McGill \\ University, Montreal, Quebec H3A 1A4, Canada, and ${ }^{8}$ Alan Edwards Pain Management Unit and ${ }^{9}$ Division of Orthopaedics, McGill University Health \\ Centre, Montreal, Quebec H3G 1A4, Canada
}

Chronic pain is associated with reduced brain gray matter and impaired cognitive ability. In this longitudinal study, we assessed whether neuroanatomical and functional abnormalities were reversible and dependent on treatment outcomes. We acquired MRI scans from chronic low back pain (CLBP) patients before $(n=18)$ and 6 months after (spine surgery or facet joint injections; $n=14)$ treatment. In addition, we scanned 16 healthy controls, 10 of which returned 6 months after the first visit. We performed cortical thickness analysis on structural MRI scans, and subjects performed a cognitive task during the functional MRI. We compared patients and controls, as well as patients before versus after treatment. After treatment, patients had increased cortical thickness in the left dorsolateral prefrontal cortex (DLPFC), which was thinner before treatment compared with controls. Increased DLPFC thickness correlated with the reduction of both pain and physical disability. Additionally, increased thickness in primary motor cortex was associated specifically with reduced physical disability, and right anterior insula was associated specifically with reduced pain. Left DLPFC activity during an attention-demanding cognitive task was abnormal before treatment, but normalized following treatment. These data indicate that functional and structural brain abnormalities - specifically in the left DLPFC_are reversible, suggesting that treating chronic pain can restore normal brain function in humans.

\section{Introduction}

Chronic low back pain (CLBP) is the most prevalent form of chronic pain, and it is the most common reason for disability in the working-age population (Rapoport et al., 2004). CLBP has been associated with abnormal brain anatomy and function. When compared with pain-free controls, individuals with CLBP have been shown to have reductions in cortical gray matter in the bilateral dorsolateral prefrontal cortex (DLPFC), thalamus, brainstem, primary somatosensory cortex (S1), and posterior parietal cortex (Apkarian et al., 2004b; Schmidt-Wilcke et al., 2006;

Received Oct. 7, 2010; Revised April 10, 2011; accepted April 12, 2011.

Author contributions: D.A.S., M.C.B., Y.S., J.A.O., and L.S.S. designed research; D.A.S., T.H.W., L.N., Z.H.-K., S.F., M.A.W., P.J., Y.S., and J.A.O. performed research; D.A.S. analyzed data; D.A.S., T.H.W., M.C.B., and L.S.S. wrote the paper.

This work was supported by an Early Career Award from the International Association for the Study of Pain (D.A.S.); Canadian Institutes for Health Research (CIHR) Fellowship MFE-84987 (D.A.S.); the Biology of Pain Young Investigator Award jointly funded by the (IHR, AstraZeneca, Canadian Pain Society Award XCP-83755 (L.S.S.); Bourse de chercheur-boursier "Junior 2" Award 14312 from the Fonds de la recherche en santé du Québec (L.S.S.), the Louise and Alan Edwards Foundation (L.S.S., D.A.S., Y.S., M.A.W.), the Institut de recherche Robert-Sauvé en santé et en securité du Travail (T.H.W.), and the Physiotherapy Foundation of Canada (T.H.W.). We thank Sylvie Toupin, Dee Anne Naylor, Linda Ferguson, and Dr. Marcos Amorim for administrative support, and Dr. Marie-Martine Langlois for her valuable time and assistance.

Correspondence should be addressed to Dr. Laura S. Stone, McGill University, Faculty of Dentistry, Alan Edwards Centre for Research on Pain, 740 Penfield Avenue, Suite 3200, Montreal, QC H3A 1A9, Canada. E-mail: laura.s.stone@mcgill.ca.

DOI:10.1523/JNEUROSCI.5280-10.2011

Copyright $\odot 2011$ the authors $\quad 0270-6474 / 11 / 317540-11 \$ 15.00 / 0$
Buckalew et al., 2008). In addition to CLBP, cortical abnormalities occur in a wide variety of other chronic pain conditions, such as chronic headache, arthritis, and fibromyalgia (for review, see May, 2008). Several studies have also indicated abnormal cortical function in people with CLBP (Giesecke et al., 2004; Baliki et al., 2008; Lloyd et al., 2008; Kobayashi et al., 2009; Tagliazucchi et al., 2010). Evidence from pain neuroimaging and transcranial magnetic stimulation studies has linked the DLPFC to pain modulation (Lorenz et al., 2003; Brighina et al., 2004; Fierro et al., 2010), placebo analgesia (Wager et al., 2004; Krummenacher et al., 2010), perceived control of pain (Pariente et al., 2005; Wiech et al., 2006), and pain catastrophizing (Seminowicz and Davis, 2006).

There is evidence that some people with chronic pain also have cognitive impairment (Kewman et al., 1991; Eccleston, 1995; Lorenz et al., 1997; Park et al., 2001; Dick et al., 2002, 2003; Apkarian et al., 2004a; Harman and Ruyak, 2005; Veldhuijzen et al., 2006; Lee et al., 2010). Findings from a recent study in healthy individuals suggested that this cognitive impairment could be a result of the demands that pain puts on cognitive brain networks: cognitive load-related activity was enhanced by pain, and even pain alone activated this cognitive network (Seminowicz and Davis, 2007b). In that study, acute noxious stimuli were administered while healthy subjects performed a task. Here, instead of noxious stimuli, we presumed that the ongoing nature of chronic pain would alter brain activity during cognitive performance. 
Table 1. Sample characteristics

\begin{tabular}{|c|c|c|c|c|c|c|c|c|c|c|c|c|c|c|c|}
\hline & \multirow[b]{2}{*}{ Sex } & \multirow[b]{2}{*}{ Age (baseline) } & \multirow[b]{2}{*}{ Pain duration (years) } & \multicolumn{4}{|c|}{ Baseline } & \multicolumn{4}{|c|}{6 weeks } & \multicolumn{4}{|c|}{6 months } \\
\hline & & & & $n$ & SFMPQ & ODI & POMS & $n$ & SFMPQ & ODI & POMS & $n$ & SFMPQ & ODI & POMS \\
\hline \multirow[t]{4}{*}{ Controls } & 8 males, 8 females & & & & & & & & & & & & & & \\
\hline & Mean & 40 & & 16 & 0.56 & 0.50 & 2.2 & 4 & 1.00 & 0.00 & 1.50 & 10 & 1.00 & 1.20 & 1.10 \\
\hline & SD & 13.16 & & & 0.96 & 1.55 & 4.48 & & 1.41 & 0.00 & 1.29 & & 2.00 & 1.93 & 2.47 \\
\hline & Range & $22-61$ & & & $0-3$ & $0-6$ & $0-16$ & & $0-3$ & & $0-3$ & & $0-6$ & $0-6$ & $0-8$ \\
\hline \multirow[t]{4}{*}{ Patients } & 8 males, 10 females & & & & & & & & & & & & & & \\
\hline & Mean & 46 & 5 & 18 & 15.8 & 43.6 & 7.50 & 6 & 12.7 & 39.7 & 5.83 & 14 & 9.13 & 26.4 & 2.06 \\
\hline & SD & 10.64 & 4.75 & & 9.27 & 14.88 & 5.23 & & 7.99 & 24.74 & 4.54 & & 7.17 & 18.67 & 3.00 \\
\hline & Range & $28-64$ & $1-20$ & & $5-43$ & $16-68$ & $0-19$ & & $0-25$ & $0-62$ & $2-12$ & & $0-21$ & $6-64$ & $0-10$ \\
\hline
\end{tabular}

6 weeks/ 6 months refers to time after baseline visit. $n$, Sample size at given time point. SFMPQ, Total score on the Short-Form McGill Pain Questionnaire; ODI, Oswestry Disability Index, percentage disability; POMS, Depression-Dejection subscale from Profile of Mood States.

Thus, we hypothesized that chronic pain would be associated with relatively greater recruitment of the cognitive brain network activated during an attention-demanding task.

We performed a longitudinal anatomical and functional MRI study with CLBP patients and healthy controls to (1) identify structural and functional differences between controls and patients before treatment, (2) determine whether these differences were reversed following treatment, and (3) establish whether these changes were linked to the amount of treatment-related reduction of pain and disability.

\section{Materials and Methods}

Participants and study design. Eighteen patients (for sample descriptive statistics, see Table 1 and supplemental Table S1, available at www. jneurosci.org as supplemental material) with CLBP of intensity at least 4 of 10 for at least 1 year participated before treatment and 6 months following treatment ( $n=14$ for 6 month posttreatment group). Low back pain patients were recruited sequentially in an outpatient orthopedic spine clinic or multidisciplinary pain center. Exclusion criteria included pain duration of less than 1 year; pain intensity less than 4 of 10, other chronic pain condition, neurological or psychological disorder, other major illness such as cancer, inability to undergo MRI, pregnancy, or under age 18 or over 65 . Patients enrolled in the study continued their normal pharmacological treatment for pain (for details, see supplemental material, available at www.jneurosci.org). Sixteen healthy, pain-free, age- and sex-matched controls also participated, and 10 of those subjects returned 6 months following the first visit. As well, four controls and six patients returned at 6 weeks after treatment. At each study session, subjects were given questionnaires to assess pain and pain-related disability and underwent MRI. The CLBP intervention was either spine surgery ( 8 of the patients in the posttreatment group) or zygapophysial (facet) joint block ( 6 of the patients in the posttreatment group) as per physician recommendations (for details on diagnosis and treatment, see supplemental Table S2, available at www.jneurosci.org as supplemental material). Subjects with other chronic pain disorders or complicating medical factors were excluded. See Table 1, supplemental Tables S1, S2, and S3 (available at www.jneurosci.org as supplemental material), and Materials and Methods for details on the sample. The procedures were approved by the McGill University Faculty of Medicine Institutional Review Board, the Montreal Neurological Institute and Hospital Research Ethics Board, and the McGill University Health Centre Research Ethics Office.

Questionnaires. Pain was assessed using the Short-Form McGill Pain Questionnaire (SFMPQ) in which subjects rated the intensity of pain descriptors (e.g., "stabbing") on a scale from 0 (none) to 3 (severe) (Melzack, 1987) (for information on numerical rating scale data, see supplemental material, available at www.jneurosci.org). Pain-related disability was determined using the Oswestry Disability Index (ODI) in which subjects rated statements that best describe how pain affects different aspects of life (e.g., "Pain has restricted my social life to home") (Fairbank et al., 1980). Subjects also completed the Profile of Mood States (POMS), in which they rated how given words (e.g. "anxious") describe how they currently feel (McNair et al., 1971).
MRI. MRI scans were acquired on a 3T Siemens TIM Trio scanner equipped with an eight-channel head coil. An anatomical scan was acquired at the beginning of the session and lasted $5 \mathrm{~min}$. The following parameters were used: echo time (TE) $3 \mathrm{~ms}$, repetition time (TR) $2.3 \mathrm{~s}$, flip angle $9^{\circ}$, resolution $1 \times 1 \times 1 \mathrm{~mm}$. During a functional scan of $\sim 5$ min, subjects performed the Multi-Source Interference Task (MSIT) as described by Seminowicz and Davis (2007a) and adapted from Bush et al. (2003). The task stimuli were presented on a screen in the subjects' view while lying in the MRI scanner, and subjects responded on a three-button response box. The task had three levels of difficulty, a motor control task (tapping), an easy level, and a difficult level. Difficultly level was based on the amount of cognitive interference. In the most difficult level of the task, the target character is a number displayed with other numbers of varying size. This difficult task was contrasted with the motor control task, in which an asterisk moved across the three positions in sequential order. The parameters for the functional scan were as follows: echoplanar imaging, TE $3 \mathrm{~ms}$, TR $2.26 \mathrm{~s}$, flip angle $90^{\circ}, 128$ frames, $64 \times 64$ matrix, 38 slices for whole-brain coverage, resolution $4 \times 4 \times 4 \mathrm{~mm}$. Images were acquired in the axial plane, plus $30^{\circ}$ from the anterior commissure-posterior commissure line to avoid the eyes.

Analysis. For preprocessing of cortical thickness, we used the CIVET pipeline (Version 1.1.9; Zijdenbos et al., 2002; Ad-Dab'bagh et al., 2006). A detailed description of the steps can be found in Fahim et al. (2010). In brief, the steps included nonuniformity correction to correct for field inhomogeneity (Sled et al., 1998), normalization (nonlinear and linear steps) to the MNI/ICBM 152 template (Collins et al., 1994, 1995), tissue classification [labeling each voxel as gray matter (GM), white matter (WM), or CSF], and partial volume estimation (Tohka et al., 2004), which labels voxels as partially GM, WM, and/or CSF (e.g., a voxel covering the pial boundary could be labeled 50\% GM, 50\% CSF). A cortical-fitting stage registers the brain surfaces to a model that calculates 81,924 vertices, which are then back-transformed to the original brains to calculate thickness in millimeters at each vertex for each brain (MacDonald et al., 2000; Kabani et al., 2001; Kim et al., 2005). A final surface registration step was performed (Lyttelton et al., 2007), followed by applying a diffusion-smoothing kernel of $30 \mathrm{~mm}$ (Chung et al., 2003).

We used SurfStat (http://www.math.mcgill.ca/keith/surfstat/) for cortical thickness analysis. For comparisons between controls and patients, we applied a general linear model (GLM) comparing groups, with age as a covariate of no interest. We performed separate GLMs for controls versus patients before treatment and controls versus patients after treatment. We also ran a mixed-effects (repeated-measures) model to examine patients before versus after treatment, with subject as the random (within-subject) effect and time (before or after treatment) as the fixed effect. This analysis included the 11 patients who responded to treatment, which was defined as a reduction in score on either the ODI or SFMPQ, with no increase on either scale. For all analyses, corrections for multiple comparisons across the whole brain were performed using random field theory-based cluster analysis (Worsley et al., 1996). For the analysis of patients before versus after treatment, we set a threshold so that only contiguous voxels with a $p$ value of $>0.001$ could be considered in the cluster analysis. This strict correction for multiple comparisons is 

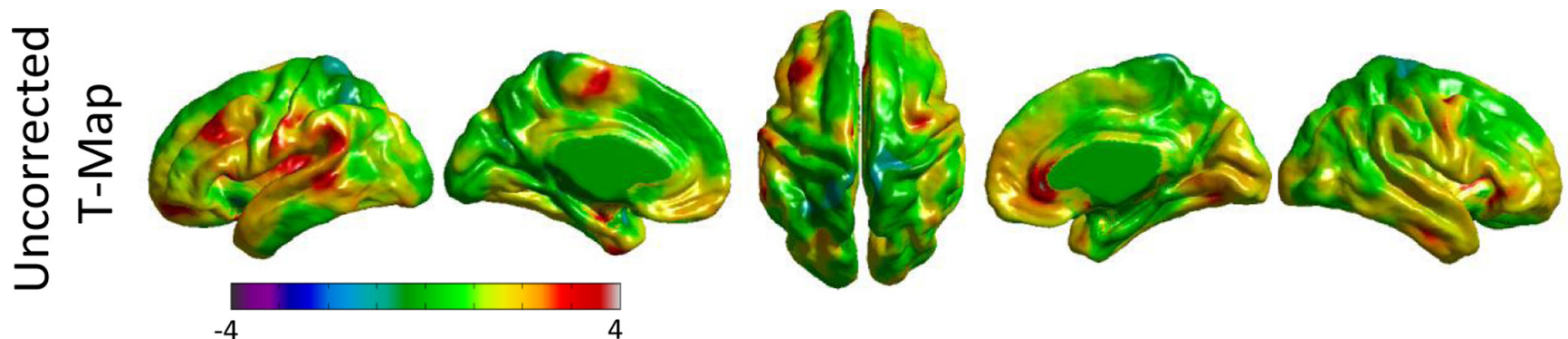

$-4$
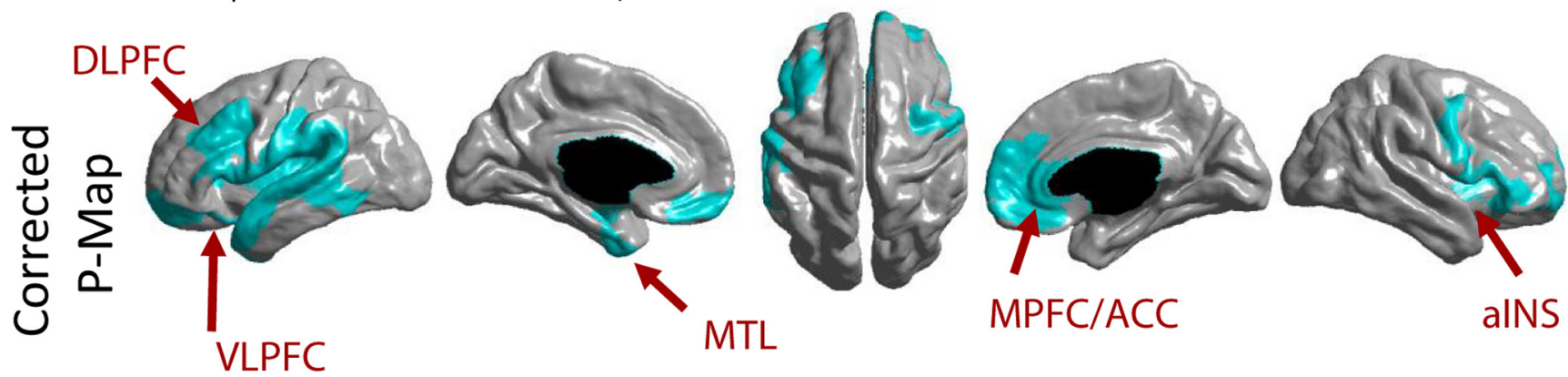

Figure 1. Cortical thickness in CLBP patients $(n=18)$ compared with controls $(n=16)$. Top row, Uncorrected $t$-value maps. Positive tvalues (red/yellow) represent areas of thinner cortexin CLBP patients than controls. Bottom row, Random-field theory-based cluster-corrected $p<0.05$ maps. Blue areas represent clusters that are significantly thinner in CLBP patients than controls. Arrows point to significant peaks listed in Table 2. Scale bar shows $t$ values. MTL, Medial temporal lobe; VLPFC, ventrolateral prefrontal cortex.

ideal for exploratory analyses. For the comparisons between controls and patients, we used a slightly more liberal initial threshold of $p<0.05$ given that previous studies have shown the effects of chronic back pain on brain anatomy (Apkarian et al., 2004b; Schmidt-Wilcke et al., 2006; Buckalew et al., 2008). In analyses where we controlled for depression, we used the POMS Depression-Dejection subscale scores as a covariate of no interest.

For fMRI data preprocessing and analysis, we used SPM8 (http://www. fil.ion.ucl.ac.uk/spm/). Preprocessing involved realignment, normalization, and smoothing at $8 \mathrm{~mm}$ FWHM. Analysis involved a mixed-effects model approach, where individual data were analyzed with the task conditions and motion parameters as regressors in a GLM (first-level analysis). In the second-level analyses, we used the results images from each individual in two-sample $t$ tests (for controls vs patients) or paired $t$ tests (for patients before vs after treatment). We used age as a covariate of no interest in the two-sample $t$ tests.

To determine the regions activated overall in patients and controls, we applied a threshold of FWE-corrected $p<0.05$ at the peak level for all subjects at the initial time point $(n=34)$. Because we had a specific hypothesis about the left DLPFC in the group comparisons and in the pre-post comparisons, we used an uncorrected $p<0.001$ for these analyses, and we report all results from these analyses. For peaks in the left DLPFC, we used a small-volume correction of a 10 -mm-radius sphere around the peak of the total sample peak DLPFC deactivation $(-24,32$, 42). A binary mask was created from the contrast of patients before treatment minus controls at $p<0.001$, and this mask was used in the search for voxels that correlated with change in SFMPQ and ODI to match the method used for cortical thickness. We used the change in SFMPQ and ODI scores separately, where the dependent data were the subtraction of an individual's pretreatment contrast image from the posttreatment image. We applied a threshold of $t>3$ for this analysis.

To determine the total number of voxels activated and deactivated during task, we calculated the number of voxels above a threshold of 2 from the SPM $t$ maps for each individual on the MSIT difficult versus motor control contrast.

For the plots of the fMRI data, contrast image values (the $\beta$ for difficult task minus the $\beta$ for tapping control) were extracted for each subject.

We used PASW (Version 18.0, SPSS) for ANOVA comparing total GM, CSF, and WM between controls and patients; SFMPQ, ODI, and POMS scores before and after treatment; MSIT performance; voxel activation during the MSIT; and the correlations and partial correlations presented in Results. Graphs were prepared in GraphPad Prism 4.0.

\section{Results}

CLBP is associated with decreased cortical thickness in multiple brain areas

Relative to controls, patients before treatment had significantly thinner cortex in left DLPFC, bilateral anterior insula/frontal operculum, left mid/posterior insula, left S1, left medial temporal lobe, and right anterior cingulate cortex (ACC) (Fig. 1, Table 2). Controlling for total intracranial volume (sum of total GM, WM, and CSF) had no effect on the cluster analysis results. We found no group differences in total GM $\left(F_{(1,31)}=2.99, p=0.094\right)$, CSF $\left(F_{(1,31)}=2.457, p=0.127\right)$, or WM $\left(F_{(1,31)}=0.072, p=0.791\right)$.

\section{Treating CLBP leads to increased cortical thickness in the left DLPFC}

Compared with controls, patients following treatment still had thinner cortex in all the same clusters except the left DLPFC, which no longer showed a significant difference between groups (Fig. 2, Table 2). Nowhere in the brain did patients have thicker cortex than controls.

Because we hypothesized that the changes in cortical thickness would depend on treatment outcome, we identified 11 of the 14 patients as responders. The 11 responders had reductions in pain [SFMPQ; pre/post mean $(\mathrm{SEM})=18.8(2.94) / 8.18(1.99), F_{(1,10)}=$ 8.30, $p<0.05,44 \%$ reduction] and/or pain-related disability $\left[\right.$ ODI; pre/post $=47.5(4.89) / 22.0(5.45), F_{(1,10)}=17.2, p<$ $0.005,46 \%$ reduction] after treatment. The remaining three patients reported worse outcomes on either the SFMPQ or ODI, and were classified as nonresponders [SFMPQ: pre/post $=13.0$ (5.69)/17.3 (2.03); ODI: pre/post $=37.3(10.5) / 39.3$ (13.5)]. Individuals' scores on SFMPQ, ODI, and POMS Depression-Dejection subscale are shown in Table 1 and supplemental Table S1 (available at www.jneurosci.org as supplemental material).

After strict correction for multiple comparisons across the brain, only one region-the left DLPFC (middle frontal gyrus, Brodmann area 9, peak coordinate in MNI standard space -45 , $33,24, t=7.70, p<0.00001)$ - had a significant increase in cortical thickness (Fig. 2D,E) in responders. On an individual basis, increases in cortical thickness were observed in every sub- 
Table 2. Cortical thickness cluster and peak statistics

\begin{tabular}{|c|c|c|c|c|c|c|c|}
\hline Cluster no. & & BA & $\mathrm{R} / \mathrm{L}$ & $x, y, z$ (MNI coordinates) & Peak $t$ value & Number of vertices in cluster & FWE-corrected $p$ value for cluster \\
\hline \multicolumn{8}{|c|}{ Controls $>$ patients before treatment (removing age) } \\
\hline \multirow[t]{3}{*}{1} & Temporal/inferior frontal & & $\mathrm{L}$ & & & 2106 & 0.000008 \\
\hline & Medial temporal (MTL) & $28 / 34$ & & $-32,-6,-22$ & 3.91 & & \\
\hline & Inferior frontal gyrus (VLPFC) & 47 & & $-25,14,-21$ & 3.64 & & \\
\hline \multirow[t]{2}{*}{2} & Insula/frontal operculum/M1 & & $\mathrm{R}$ & & & 2336 & 0.000009 \\
\hline & Anterior insula (aINS) & - & & $32,19,7$ & 3.94 & & \\
\hline \multirow[t]{2}{*}{3} & Prefrontal/insula/S2/superior temporal & & $\mathrm{L}$ & & & 7123 & 0.000042 \\
\hline & DLPFC & 9 & & $-42,31,32$ & 3.69 & & \\
\hline \multirow[t]{3}{*}{4} & MPFC/ACC & & $\mathrm{R}$ & & & 2377 & 0.00375 \\
\hline & $\mathrm{pACC} / \mathrm{sACC}$ & 24 & & $3,35,0$ & 4.07 & & \\
\hline & SACC & 24 & & $3,34,-3$ & 3.69 & & \\
\hline 5 & Visual (no peaks $t>3.5$ ) & & $\mathrm{R}$ & & & 2029 & 0.0779 (NS) \\
\hline \multicolumn{8}{|c|}{ Controls > patients after treatment (removing age) } \\
\hline \multirow[t]{2}{*}{1} & Temporal & & $\mathrm{L}$ & & & 633 & 0.000032 \\
\hline & Medial temporal (MTL) & - & & $-25,-8,-26$ & 3.60 & & \\
\hline \multirow[t]{2}{*}{2} & Insula/frontal operculum & & $\mathrm{R}$ & & & 1906 & 0.000049 \\
\hline & Anterior insula (aINS) & - & & $32,19,7$ & 3.83 & & \\
\hline \multirow[t]{4}{*}{3} & Insula/superior temporal & & $\mathrm{L}$ & & & 4360 & 0.00046 \\
\hline & Superior temporal gyrus & 22 & & $-53,-11,4$ & 3.98 & & \\
\hline & Posterior insula/S2 (pINS/S2) & 13 & & $-42,-20,7$ & 3.63 & & \\
\hline & Anterior insula/frontal operculum & 13 & & $-43,21,4$ & 3.58 & & \\
\hline 4 & Visual (no peaks $t>3.5$ ) & & & & & 2910 & 0.0137 \\
\hline \multicolumn{8}{|c|}{ Patients after treatment $>$ patients before treatment (treatment responders only, $n=11$ ) } \\
\hline \multirow[t]{2}{*}{1} & Prefrontal & & $\mathrm{L}$ & & & 449 & 0.0053 \\
\hline & DLPFC & 9 & & $-45,33,24$ & 7.70 & & \\
\hline
\end{tabular}

BA, Brodmann areas; $\mathrm{PACC}$, pregenual anterior cingulate cortex; $5 \mathrm{ACC}$, subgenual anterior cingulate cortex; VLPFC, ventrolateral prefrontal cortex; $\mathrm{S2}$, secondary somatosensory cortex.

ject who responded to treatment. This is in contrast to decreases in cortical thickness in the same region that were observed in two of the three nonresponders. Figure $2 F$ shows pretreatment and posttreatment thickness for all patients in the sample. When all 14 patients were included in a repeated-measures analysis comparing before versus after treatment, there were no significant differences in cortical thickness after correction for multiple comparisons. These data indicate that the left DLPFC is abnormally thin in untreated CLBP, and that effective treatment-in this study, any reduction in pain or pain-related disability_leads to increased thickness in this area.

\section{Recovery of cortical thickness is independent of depression} In responders, depression scores decreased from 8.81 (SEM = $1.70)$ before treatment to $1.64(\mathrm{SEM}=0.92)$ following treatment $\left(F_{(1,10)}=15.5, p<0.005\right)$. We controlled for depression in the analyses comparing patients with controls, as well as before versus after treatment within patients. After controlling for depression, the difference between controls and patients before treatment was slightly reduced, but the left DLPFC cluster was still significantly thinner in patients than controls $(p<$ 0.00005 vs $p<0.0005)$. Similarly, the DLPFC was still significantly thicker after than before treatment after controlling for depression $(p<0.005$ vs $p<0.001)$. In contrast, the medial prefrontal cortex/anterior cingulate cortex cluster (MPFC/ACC) was no longer significantly thinner in patients before treatment than controls after controlling for depression $(p<0.005$ vs $p>$ $0.3)$.

The extent of thickness increase in left DLPFC and other areas is associated with effectiveness of treatment

We examined the relationship between treatment-related changes in pain, pain-related disability, and the cortical thickness of areas that were shown to be thinner before treatment in patients compared with controls (the blue areas in Fig. 1). Specifi- cally, we searched for regions where the change in thickness from before to after treatment correlated with the magnitude of treatment-related changes in SFMPQ or ODI scores. For both SFMPQ and ODI, peak values were identified in the left DLPFC (for ODI, coordinates were $-43,18,30, t=3.33$; for SFMPQ, $-45,24,27, t=3.43)$ and the S2/posterior insula $(-61,-27,23$; same peak for ODI, $t=2.68$, and SFMPQ, $t=3.50)$, where recovery of cortical thickness was significantly correlated with reduced pain intensity and improvement in physical disability. Because change in SFMPQ and change in ODI were highly correlated ( $r=0.74, p<0.005$, two-tailed), it was not surprising that similar areas were related to these measures. However, improvement in physical disability also correlated with posttreatment thickening of left primary motor cortex (M1), even after controlling for SFMPQ ( $r=0.60, p<0.05$, two-tailed $)$, and SFMPQ also correlated with increased thickness in right anterior insula (aINS) after controlling for ODI $(r=0.59, p<0.05)$ (Fig. 3). Note that all patients were included in these analyses.

\section{CLBP patients have abnormal left DLPFC activation during} cognitive challenge, despite normal performance on the task Reaction times on the difficult task did not differ significantly between controls and patients before treatment $\left(F_{(1,33)}=1.18\right.$, $p>0.1)$ or between patients before and after treatment $\left(F_{(1,13)}=\right.$ $2.96, p>0.1)$. Performance of the difficult task compared with the tapping-only condition led to activations in regions of the task-positive network and deactivations in the task-negative network as described by Fox et al. (2005). Although the task-related activations and deactivations were similar for each group, we noticed qualitatively that patients had overall more activations and fewer deactivations. In Figure $4 A$, patients (blue) had a greater area of task-related activations than controls (red); areas of overlap are shown in pink. In Figure $4 B$, patients (green) had fewer task-related deactivations than controls (red); areas of overlap are shown in yellow. In Figure $4 C$, we show a contrast 
A
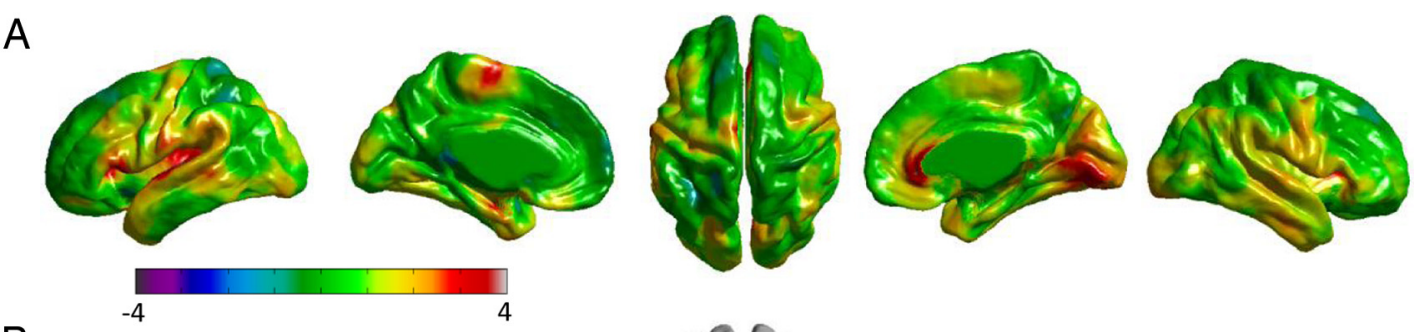

B
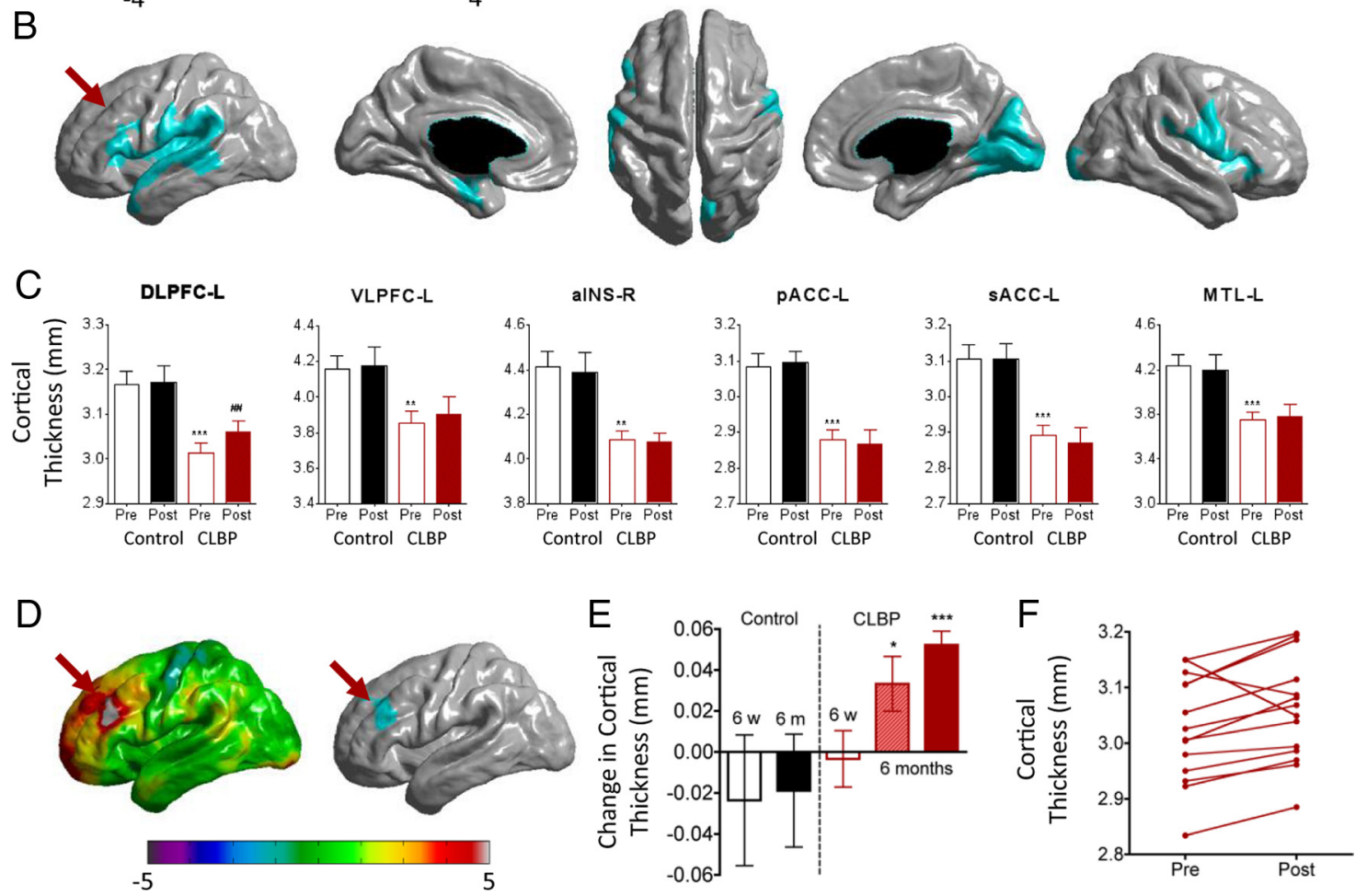

Figure 2. Cortical thickness changes in patients after treatment. $A, t$-value maps comparing cortical thickness after treatment compared with controls. Positive $t$ values (red/yellow) represent thinner cortex in CLBP patients. $\boldsymbol{B}, p$-value maps, cluster-corrected $p<0.05$, corresponding to $A$. Note that the left DLPFC (arrow) is no longer significantly different between groups, as it was before treatment. C, Cortical thickness values for CLBP patients and controls before and after treatment for the significant peaks shown in Figure 1 and Table 2. Note that only the left DLPFC showed an increase in cortical thickness after versus before treatment. ${ }^{* *} p<0.01$, ${ }^{* * *} p<0.001$, compared to controls; ${ }^{\# \#} p<0.001$, paired $t$ test $(n=14)$ CLBP before versus after treatment. $D, t$ - and $p$-value maps for patients who responded to treatment $(n=11)$ showing that the left DLPFC became thicker in patients after treatment compared with before treatment (arrow). $\boldsymbol{E}$, Differences in DLPFC thickness for controls and patients 6 weeks $(6 \mathrm{w})$ and 6 months $(6 \mathrm{~m})$ after treatment. At 6 months, data are shown for all patients (hatched red bar) as well as limited to those who responded to treatment (solid red bar). ${ }^{* *} p<0.01,{ }^{* * *} p<0.001$, one-sample $t$ test, before treatment, CLBP versus controls. $\boldsymbol{F}$, Pretreatment versus posttreatment line plots for each patient. Note that the majority of individuals showed an upward trend. MTL, Medial temporal lobe; VLPFC, ventrolateral prefrontal cortex.

map of patients $>$ controls (red) and controls $>$ patients (blue) at a very liberal threshold $(p<0.05)$ to illustrate that, overall, patients have far more widespread relative activation than controls. We extracted from each subject's $t$ maps all values below -2 (deactivations) and above 2 (activations) and plotted these average values (Fig. $4 D$ ). For the pretreatment time point, the mean number of voxels activated (SEM) was 36,963 (6574) in controls versus $52,380(6180)$ in patients $\left(F_{(1,33)}=1.58, p>0.1\right)$, and the number of voxels deactivated was 19,276 (5704) in controls versus $12,782(3200)$ in patients $\left(F_{(1,33)}=1.04, p>0.1\right)$.

Patients $(n=18)$ before treatment had relatively more taskrelated activity in several regions compared with controls, including a peak in the left DLPFC (Table 3) $[-16,28,40, t=3.44, p<$ 0.05 small-volume corrected (see Materials and Methods)]) (Fig. $4 E$ ). The plot in Figure $4 F$ shows that patients did not deactivate this area as strongly as controls. Following treatment, activity in patients $(n=14)$ in only one region-the left DLPFC—-was deactivated relative to before treatment (paired $t$ test; $-28,24,44$, $t=4.36, p<0.05$ small-volume corrected) (Table 3, Fig. 5). Thus, following treatment, pain-related abnormalities in the left
DLPFC returned toward control values. There were no areas where controls had relatively more activation than patients before treatment, nor were there any areas that were relatively more activated in patients after versus before treatment. Controlling for depression in the pretreatment versus posttreatment comparison did not reduce the significance of the DLPFC change $(-30$, $24,42, t=5.66, p<0.01$, small-volume corrected). There was no significant change in task performance after treatment, and the difference between pretreatment and posttreatment task reaction times did not correlate with the change in DLPFC activity $(r=$ $0.16, p>0.5$ ), suggesting that the change in left DLPFC was not simply related to improved task performance.

Unlike our data demonstrating an association between increasing cortical thickness and treatment outcomes, there was no correlation between the extent of reduced pain or painrelated disability (SFMPQ and ODI scores, respectively) and the amount of reduction in left DLPFC activity during the cognitive task after versus before treatment. Furthermore, the pretreatment to posttreatment changes in left DLPFC thickness and left DLPFC deactivation were not correlated in all 

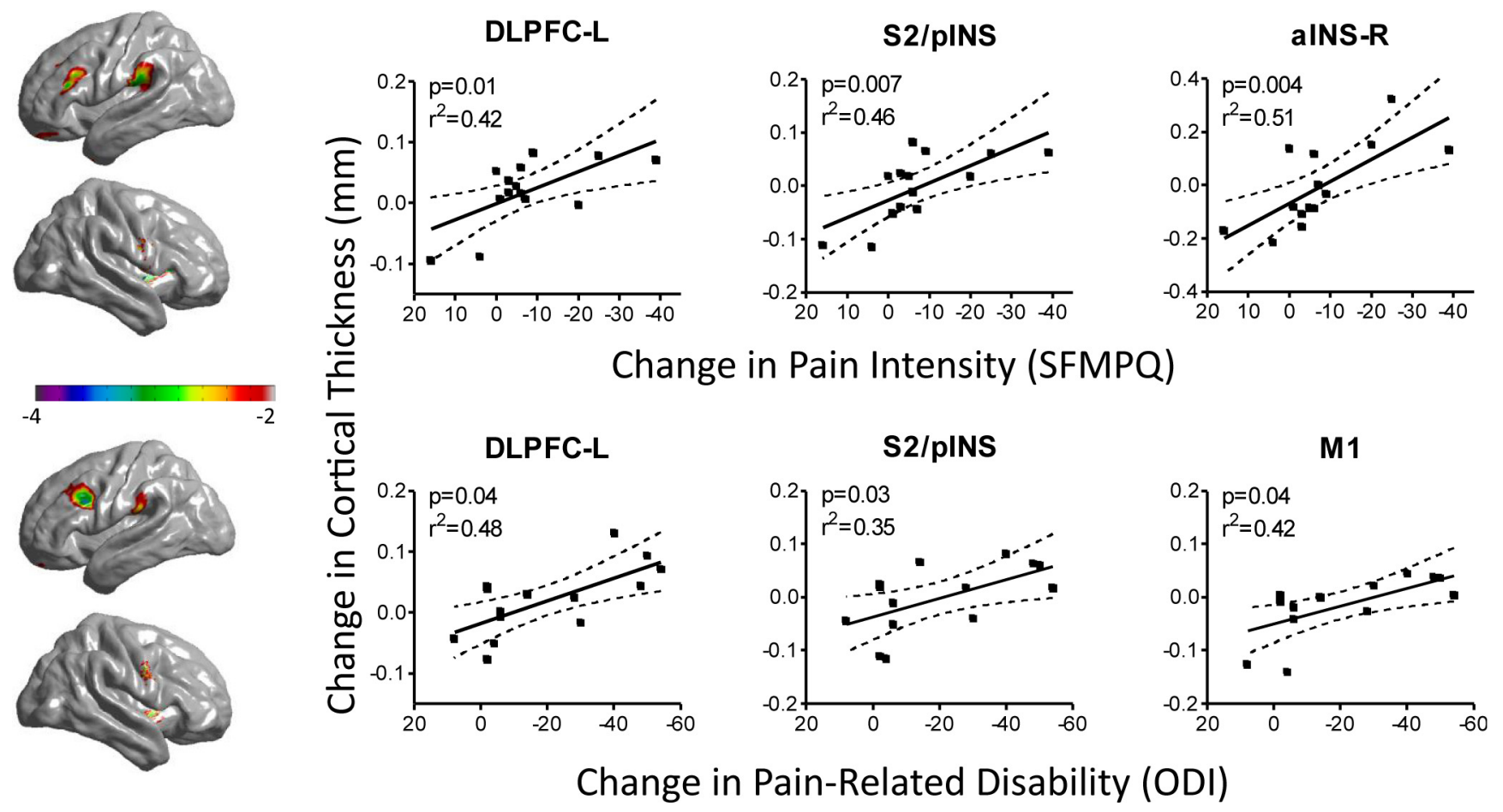

Figure 3. Relationship between changes in pain, disability, and cortical thickness before versus after treatment. Left, Uncorrected $t$-value maps for the whole-brain correlations between pretreatment versus posttreatment cortical thickness and pain (SFMPQ, top panel) or pain-related disability (ODI, bottom panel). For these analyses, the search was limited to regions that were statistically different in controls compared with patients before treatment. Right, Scatterplots depicting the relationship between changes in cortical thickness and pain (SFMPQ, top panel) or disability (ODI, bottom panel) are shown for each significant peak. The analyses and plots include all 14 patients; $p$ values on the plots are based on one-tailed $t$ tests.

patients $(r=0.103, p=0.72, n=14)$ or in responders only $(r=0.214, p=0.53, n=11)$.

\section{What comes first, anatomical or functional changes in left DLPFC?}

A small subset of the subjects (4 controls and 6 patients) also participated in a session at 6 weeks after treatment, in addition to before treatment and 6 months after treatment. Although we considered the groups too small for statistical comparison, the plots in Figures $2 E$ and $5 A$ and in supplemental Figure S1 (available at www.jneurosci.org as supplemental material) illustrate the contrast between the lack of change in cortical thickness at 6 weeks compared with the large change in functional activity at that same time point. We also have included plots of individuals' changes (for data from the peaks in the analyses of patients before vs after treatment) in supplemental Figure S1 (available at www. jneurosci.org as supplemental material). For the functional data, at 6 weeks the activity level is intermediate to the pretreatment and 6 month posttreatment time points, whereas for cortical thickness, the 6 week data do not seem to be related to the 6 month change. This result suggests that the functional change occurs early, whereas more time is needed for the structural change. Note that because some of the subjects participated at the 6 week time point, this can only be regarded as only a preliminary finding.

\section{Discussion}

Our findings provide strong evidence that pain-related neuroanatomical and functional changes are reversible with effective treatment. Furthermore, we have provided evidence for a link between regional brain function and anatomy. The left DLPFC was thinner and was activated abnormally in patients before treatment relative to controls; after treatment, the same region became thicker and also functioned more similarly to controls on a cognitive task. Previous research has shown altered brain anatomy in chronic pain conditions (Apkarian et al., 2004b; SchmidtWilcke et al., 2005, 2006; Kuchinad et al., 2007; Buckalew et al., 2008; Geha et al., 2008; Lutz et al., 2008; Schweinhardt et al., 2008; Teutsch et al., 2008; Hsu et al., 2009; Obermann et al., 2009; Rodriguez-Raecke et al., 2009; Wood et al., 2009; Gwilym et al., 2010; Seminowicz et al., 2010; Tu et al., 2010), and other studies have linked cortical thickness to cognitive function (Hadjikhani et al., 2007; Dickerson et al., 2008; Sowell et al., 2008). To our knowledge, no other study has shown a link between gray matter density or cortical thickness loss and altered cognitive taskrelated brain activity in chronic pain.

\section{Treating CLBP results in increased cortical thickness in left DLPFC}

Recent studies suggest that changes in brain gray matter can occur when pain is eliminated (Obermann et al., 2009; RodriguezRaecke et al., 2009; Gwilym et al., 2010). The current study extends those findings to changes in cortical thickness, which is a quantitative measure that can be compared between studies, unlike gray matter density. Furthermore, we demonstrate that the left DLPFC got thicker in each CLBP patient who improved after treatment, and that the amount of neuroanatomical recovery depended on the amount of improvement in clinical outcome measures in each patient. The patients in our sample received treatment interventions that targeted the presumed pain generators within the musculoskeletal system (i.e., spinal structures). The mechanisms by which these interventions result in changes in the DLPFC are currently unclear. A recent longitudinal study in rats reported that ongoing chronic pain resulted in reduced gray matter in the prefrontal cortex that was temporally correlated with the emergence of emotional disturbances (Seminowicz 
A

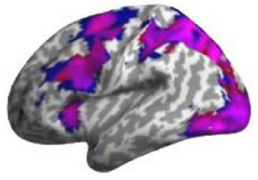

B

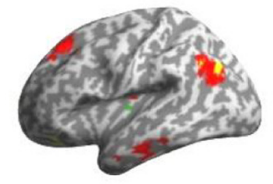

C

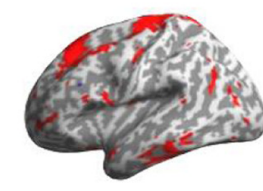

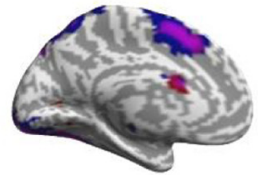
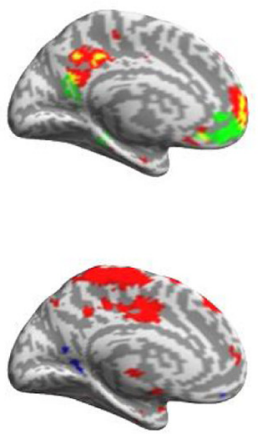
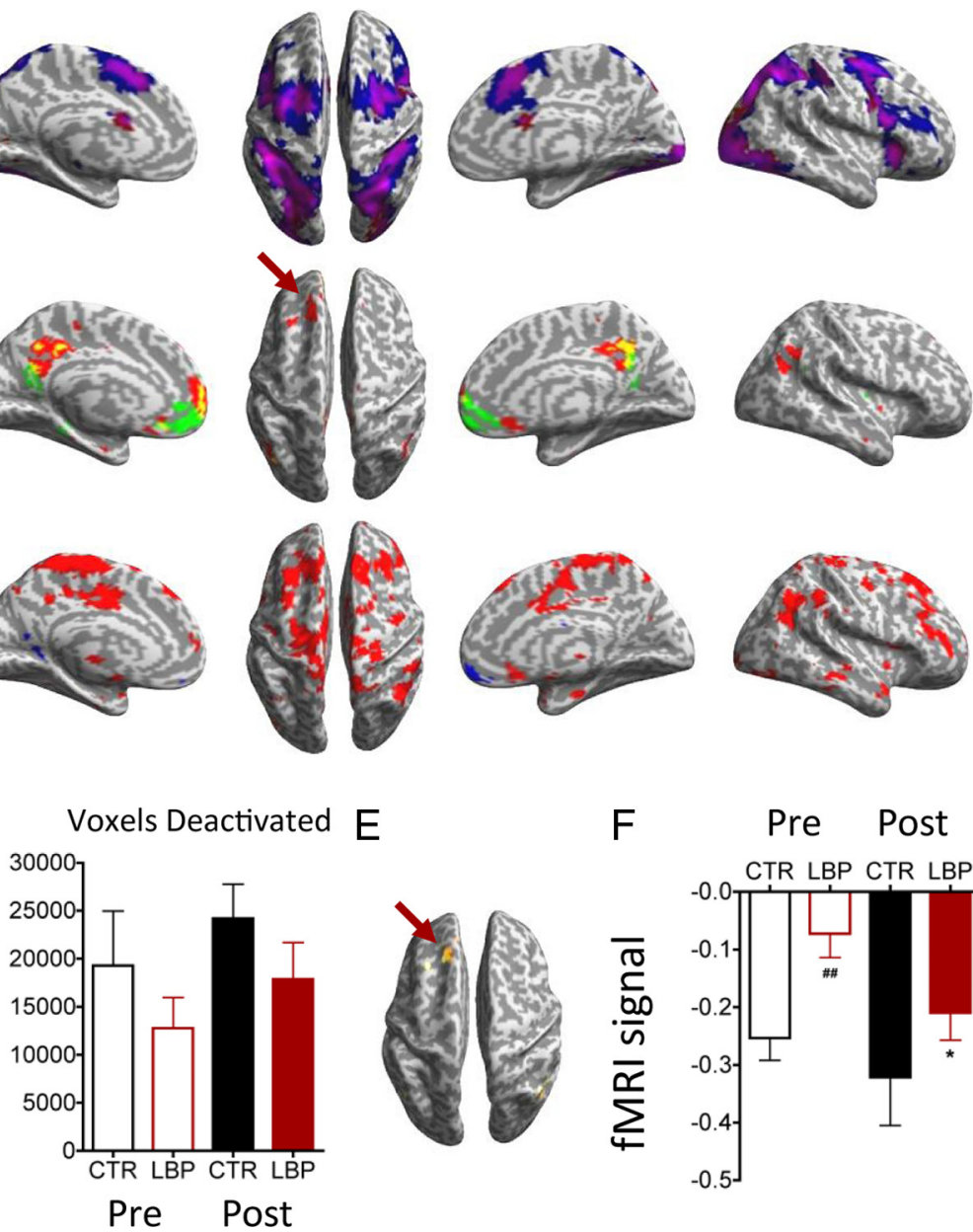

\section{$E$}

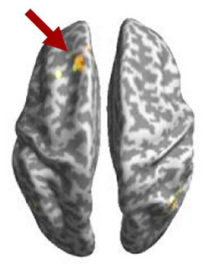

$\mathrm{F}$

Pre Post

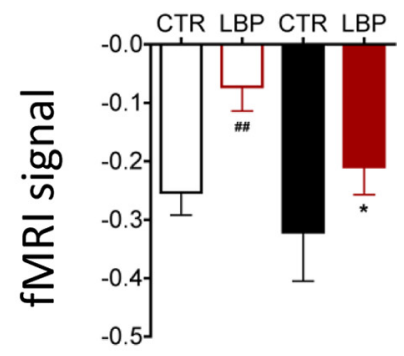

Figure 4. MSIT activations in CLBP patients and controls. $\boldsymbol{A}$, Task-related activations in patients (blue) and controls (red). Areas of overlap are shown in pink. Note greater area of activation in patients. $\boldsymbol{B}$, Task-related deactivations in patients (green) and controls (red). Areas of overlap are shown in yellow. Arrow, Deactivation of the DLPFC is observed in controls but not patients. $\boldsymbol{C}$, Contrast maps of patients $>$ controls (red) and controls $>$ patients (blue) at a very liberal threshold $(p<0.05)$, illustrating that overall patients have far more widespread relative activation than controls. $\boldsymbol{D}$, Average total number of voxels activated $(t>2)$ or deactivated $(t<-2)$ in patients (LBP) and controls (CTR). Note the trend for more activated and fewer deactivated voxels in patients compared with controls. $\boldsymbol{E}$, Relative increased activation in the left DLPFC (arrow) in patients before treatment compared with controls. $\boldsymbol{F}$, Activity in the left DLPFC region shown in $\boldsymbol{E}$, for patients and controls before and after treatment, where patients return toward normal activity levels. ${ }^{\# \#} p<0.001$, one-sample $t$ test, before treatment, CLBP versus controls; ${ }^{*} p<0.05$, paired $t$ test $(n=14$ ) CLBP before versus after treatment. All brain images are $t$ maps with threshold uncorrected $p<0.001$ for visualization. See Table 3 and text for full statistics.

et al., 2009). Thus, it seems that the development of chronic pain can lead to prefrontal cortical thinning, and-from the present results - that reducing pain can lead to prefrontal cortical thickening. It is also evident that anxiety and depression are closely related to these changes, although in both the case of the rat study and the present study, affective measures alone did not explain the differences in cortical volume or thickness. The reduction of incoming nociceptive inputs from peripheral structures likely accounts for part of the improvement in pain and pain-related disability. It will be important for future studies to determine whether interventions specifically targeting psychosocial rather than biomechanical components of chronic pain (e.g., cognitive-behavioral therapy) result in similar recovery in cortical thickness.

\section{Increases in cortical thickness correlate with clinical outcomes}

We show here that the increase in cortical thickness following treatment correlated with clinical outcomes. Whereas recovery in both the left DLPFC and S2/posterior insula (pINS) was related to general improvement after treatment (both pain and painrelated disability), physical impairment was specifically related to recovery of $\mathrm{M} 1$, and pain was specifically related to recovery of right aINS. This is consistent with both the role of M1 in motor function and the literature showing a specific role for the aINS in the estimation of pain magnitude (Baliki et al., 2009).

The outcomes for our patient sample, in which almost every patient experienced a reduction in pain, were generally better than previously reported (Cohen and Raja, 2007; Chou et al., 2009). We classified as a responder any subject who improved on either the SFMPQ or the ODI, regardless of the magnitude of the improvement. Other studies may use different criteria that result in more conservative estimates of treatment success. Furthermore, our follow-up evaluation was only 6 months after intervention. It is possible that our "responders" may go on to experience an increase in their pain and disability levels at later time points. Future studies should build on our findings by exploring similar outcomes over a longer follow-up period, and by using patients who do not respond to treatment as a control group.

\section{Impact of depression on changes in cortical thickness}

Because chronic pain and depression commonly co-occur (Krishnan et al., 1985) and because the DLPFC has been impli- 
Table 3. MSIT activation peaks

\begin{tabular}{|c|c|c|c|c|c|}
\hline & $\mathrm{BA}$ & $\mathrm{R} / \mathrm{L}$ & $x, y, z$ (MNI coordinates) & $t$ value & Voxels in cluster \\
\hline \multicolumn{6}{|c|}{ All subjects (removing age), task-positive regions ${ }^{a}$} \\
\hline \multirow[t]{2}{*}{ MT+ } & $19 / 18$ & $\mathrm{~L}$ & $-42,-82,-10$ & 10.67 & 1330 \\
\hline & 19/18 & $\mathrm{R}$ & $40,-84,-2$ & 8.52 & 2835 \\
\hline & 7 & $\mathrm{R}$ & $30,-54,48$ & 7.54 & 476 \\
\hline \multirow[t]{2}{*}{ Premotor } & 6 & $\mathrm{~L}$ & $-44,6,32$ & 7.23 & 273 \\
\hline & 6 & $\mathrm{R}$ & $52,12,28$ & 6.01 & 20 \\
\hline Pre-SMA/MCC & $24 / 32 / 6$ & $\mathrm{~L}$ & $-8,16,46$ & 6.15 & 73 \\
\hline \multicolumn{6}{|c|}{ All subjects (removing age), task-negative regions ${ }^{a}$} \\
\hline $\mathrm{PCC} /$ precuneus & 31 & - & $0,-42,40$ & 8.71 & 636 \\
\hline \multirow[t]{2}{*}{ Lateral parietal/temporal } & $40 / 7 / 39$ & $\mathrm{~L}$ & $-48,-78,32$ & 8.52 & 306 \\
\hline & $40 / 7 / 39$ & $\mathrm{R}$ & $60,-62,26$ & 7.04 & 171 \\
\hline MPFC & $10 / 9 / 32$ & - & $-2,60,8$ & 7.83 & 509 \\
\hline Dorsal MPFC & 8 & - & $2,36,54$ & 3.94 & 67 \\
\hline Cerebellum & - & $\mathrm{R}$ & $42,-78,-20$ & 3.61 & 5 \\
\hline \multirow[t]{2}{*}{ Precentral gyrus } & 4 & L & $-24,-18,62$ & 3.49 & 6 \\
\hline & 4 & $\mathrm{R}$ & $20,-18,62$ & 3.57 & 12 \\
\hline DLPFC & $9 / 8$ & $\mathrm{~L}$ & $-16,28,40$ & 3.44 & 2 \\
\hline
\end{tabular}

$\mathrm{BA}$, Brodmann areas; $\mathrm{MCC}$, midcingulate cortex; $\mathrm{PCC}$, posterior cingulate cortex.

${ }^{a}$ Analyses are corrected at peak value $p<0.05$ corrected by FWE.

${ }^{b}$ Anterior insula was part of a larger cluster at FWE-corrected $p<0.05$; the peaks were identified by increasing the threshold to FWE $p<0.01$.

$c_{p}<0.001$ uncorrected. DLPFC peaks are FWE-corrected $p<0.05$ small volume corrected in a 10-mm-radius sphere around the coordinate for all patients and controls $(-24,32,42)$.

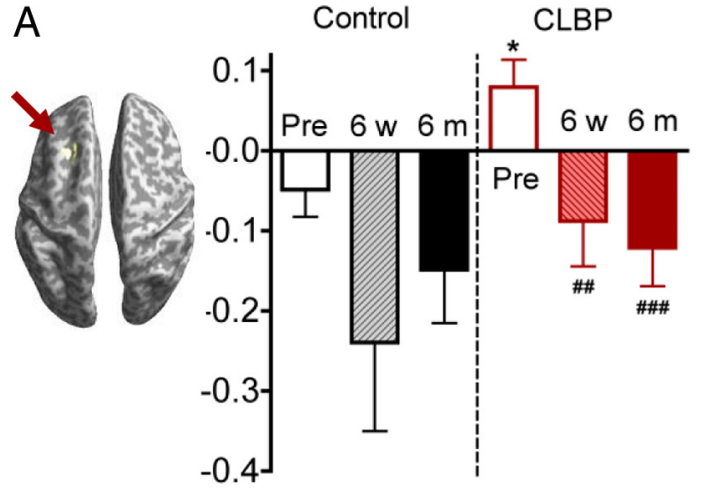

B

Figure 5. MSIT activation differences in CLBP patients before and after treatment. $A$, Patients had relatively more activity in only one area in the brain ( $p<0.001$ uncorrected), the left DLPFC, before treatment. Activity in this region normalized following treatment (plot). $B$, Line plots showing individual changes in DLPFC activity before versus 6 months after treatment. Note that almost all patients had a stronger deactivation after treatment. ${ }^{*} p<0.05$, one-sample $t$ test, before treatment, CLBP versus controls; ${ }^{\#} p<0.01,{ }^{\# \# \#} p<0.001$, paired $t$ test $(n=14)$ CLBP before versus after treatment; $6 \mathrm{w}, 6$ weeks after treatment, $6 \mathrm{~m}, 6$ months after treatment.

tion selection (Kulkarni et al., 2005; Vogt, 2005; Oshiro et al., 2009), did not show a difference between patients and controls in the present study.

Treating CLBP results in normalization of cognitive task-related brain activity in left DLPFC

During performance of a cognitively demanding task, the activation patterns in patients and controls were generally similar. However, patients activated the cognitive network to a greater extent and had relatively fewer deactivations than controls during the task. In particular, the left DLPFC is recruited and not deactivated as it was in the controls. That patients had relatively fewer deactivations is consistent with the results of Baliki et al. (2008), where CLBP patients had relatively fewer

cated in major depression (Brunelin et al., 2007; O'Reardon et al., 2007), we controlled for levels of depression in our study using the score on the POMS Depression-Dejection subscale. Although depression is an important factor in CLBP and may explain a portion of the variance between patients before treatment and controls, in the present study, it did not explain the increase in DLPFC thickness following treatment in our sample. An interesting finding was that the MPFC/ACC cluster that was thinner in patients before treatment than controls was no longer significantly thinner after controlling for depression. The ACC has aberrant activity in major depression (Mayberg, 2009) and is implicated in the affective aspect of pain (Kulkarni et al., 2005; Vogt, 2005). Note that the midcingulate cortex, which is usually activated by acute noxious stimuli and is probably related to ac- deactivations during a simple task. Although the precise role of the left DLPFC in the MSIT is unknown, this finding is consistent with previous literature showing that pain is associated with increased engagement of a cognitive network (Seminowicz and Davis, 2007b). After treatment, patients had normal task-related activity in this area, and the left DLPFC was the only area that showed a difference in activity in patients after versus before treatment, just as the left DLPFC was the only area that got thicker in patients. This strongly indicates that the change in brain structure (increase in cortical thickness in the left DLPFC) is related to function.

The functional and structural changes in left DLPFC following treatment were consistent across subjects. Regions that had dif- 
ferences in cortical thickness or cognitive task-related activity in each patient before versus after treatment were identified by repeated-measures analyses. In both cases, the left DLPFC was identified. The pretreatment and posttreatment cortical thickness and task-related activity values in this region are shown for each patient in Figures $2 F$ and $5 B$, respectively. Note that in both measures, the majority of patients show both (1) increased cortical thickness after treatment (Fig. $2 F$ ) and (2) increased deactivation after treatment (Fig. 5B). Thus, the reported changes in left DLPFC were highly consistent across individuals.

\section{Future directions}

Several important problems remain for future research to resolve. First, are the findings here specific to CLBP, or are they replicable across different chronic pain conditions, or even across other chronic diseases such as posttraumatic stress disorder, chronic fatigue syndrome, or obesity? Although brain gray matter loss in chronic pain is a consistent finding, the brain areas affected in each sample or pain condition are variable (May, 2008; Schweinhardt et al., 2008). It is, therefore, not yet certain whether the currently reported treatment-related changes are relevant to all pain conditions or only to specific groups or samples. Second, to what aspect of the treatment were the changes in DLPFC related? The patients in our study underwent one of two procedures for low back pain. In this study, we focused our analysis on changes in pain and pain-related disability, regardless of the treatment or mechanism of action. It is quite possible that a strong placebo effect, as is often seen in chronic pain (Seeley, 1990; Hoffman et al., 2005), contributed to the improved outcomes observed in this study.

Another important question is as follows: Are the changes in left DLPFC and elsewhere related to pain modulation? Several studies have indicated a role for the prefrontal cortex in pain modulation (Hardy and Haigler, 1985; Lorenz et al., 2003; Wager et al., 2004; Wiech et al., 2006; Krummenacher et al., 2010). If recovery of DLPFC thickness and/or function is necessary for pain relief, then the DLPFC may be a target for treatment. In fact, it has already shown some promise in studies of short- and longterm analgesia from repetitive transcranial magnetic stimulation (rTMS) of the prefrontal cortex (Reid and Pridmore, 2001; Brighina et al., 2004; Graff-Guerrero et al., 2005; Avery et al., 2007; Borckardt et al., 2007, 2008; Nahmias et al., 2009; Fierro et al., 2010). Interestingly, similar to treating depression with rTMS (Brunelin et al., 2007), these rTMS studies in pain seem to show a preferential effect for left-sided stimulation, the side that changed in the present study. Finally, the increased cortical thickness in S2/pINS that correlated with improvements in both pain and pain-related disability might reflect a normalization of peripheral inputs because this region has direct spinothalamic inputs. Future research should determine whether there is a direct relationship between persistent peripheral input and S2/pINS thickness.

A previous study indicated that the impact of CLBP on the brain may vary by pain type (i.e., neuropathic vs non-neuropathic) (Apkarian et al., 2004b). In the current study, the experimental group reported chronic axial low back pain, chronic radicular pain, or both. Although this strategy did not allow for differentiation between nociceptive and neuropathic pain, the sample was representative of the mixed etiology of CLBP in the general population. Furthermore, different treatment interventions (surgery or facet joint block) were selected to maximize the likelihood of pain relief for each individual patient as would be typical in a clinical setting. Rather than attempting to differentiate between differences in pain etiology or treatment selection, the primary outcome measures were posttreatment improvement in pain and disability. Future studies could be conducted to further dissect the impact of pain types and specific treatments on brain structure and function.

\section{Conclusions}

In summary, we have shown that the left DLPFC, which was thinner and had abnormal cognitive task-related activity in CLBP patients before treatment compared with pain-free controls, became significantly thicker and had normal activity following treatment, and that the degree of recovery in thickness depended on the extent of the patient's improvement after treatment. Our results imply that treating chronic pain can restore normal brain function.

\section{References}

Ad-Dab'bagh Y, Lyttelton O, Muehlboeck JS, Lepage C, Einarson D, Mok K, Ivanov O, Vincent RD, Lerch J, Fombonne E, Evans AC (2006) The CIVET image-processing environment: a fully automated comprehensive pipeline for anatomical neuroimaging research. Paper presented at the 12th Annual Meeting of the Organization for Human Brain Mapping, Florence, Italy; June.

Apkarian AV, Sosa Y, Krauss BR, Thomas PS, Fredrickson BE, Levy RE, Harden RN, Chialvo DR (2004a) Chronic pain patients are impaired on an emotional decision-making task. Pain 108:129-136.

Apkarian AV, Sosa Y, Sonty S, Levy RM, Harden RN, Parrish TB, Gitelman DR (2004b) Chronic back pain is associated with decreased prefrontal and thalamic gray matter density. J Neurosci 24:10410-10415.

Avery DH, Holtzheimer PE 3rd, Fawaz W, Russo J, Neumaier J, Dunner DL, Haynor DR, Claypoole KH, Wajdik C, Roy-Byrne P (2007) Transcranial magnetic stimulation reduces pain in patients with major depression: a sham-controlled study. J Nerv Ment Dis 195:378-381.

Baliki MN, Geha PY, Apkarian AV, Chialvo DR (2008) Beyond feeling: chronic pain hurts the brain, disrupting the default-mode network dynamics. J Neurosci 28:1398-1403.

Baliki MN, Geha PY, Apkarian AV (2009) Parsing pain perception between nociceptive representation and magnitude estimation. J Neurophysiol 101:875-887.

Borckardt JJ, Smith AR, Reeves ST, Weinstein M, Kozel FA, Nahas Z, Shelley N, Branham RK, Thomas KJ, George MS (2007) Fifteen minutes of left prefrontal repetitive transcranial magnetic stimulation acutely increases thermal pain thresholds in healthy adults. Pain Res Manag 12:287-290.

Borckardt JJ, Reeves ST, Weinstein M, Smith AR, Shelley N, Kozel FA, Nahas Z, Byrne KT, Morgan K, George MS (2008) Significant analgesic effects of one session of postoperative left prefrontal cortex repetitive transcranial magnetic stimulation: a replication study. Brain Stimul 1:122-127.

Brighina F, Piazza A, Vitello G, Aloisio A, Palermo A, Daniele O, Fierro B (2004) rTMS of the prefrontal cortex in the treatment of chronic migraine: a pilot study. J Neurol Sci 227:67-71.

Brunelin J, Poulet E, Boeuve C, Zeroug-vial H, d'Amato T, Saoud M (2007) Efficacy of repetitive transcranial magnetic stimulation (rTMS) in major depression: a review (in French). Encephale 33:126-134.

Buckalew N, Haut MW, Morrow L, Weiner D (2008) Chronic pain is associated with brain volume loss in older adults: preliminary evidence. Pain Med 9:240-248.

Bush G, Shin LM, Holmes J, Rosen BR, Vogt BA (2003) The Multi-Source Interference Task: validation study with $\mathrm{fMRI}$ in individual subjects. Mol Psychiatry 8:60-70.

Chou R, Baisden J, Carragee EJ, Resnick DK, Shaffer WO, Loeser JD (2009) Surgery for low back pain: a review of the evidence for an American Pain Society Clinical Practice Guideline. Spine 34:1094-1109.

Chung MK, Worsley KJ, Robbins S, Paus T, Taylor J, Giedd JN, Rapoport JL, Evans AC (2003) Deformation-based surface morphometry applied to gray matter deformation. Neuroimage 18:198-213.

Cohen SP, Raja SN (2007) Pathogenesis, diagnosis, and treatment of lumbar zygapophysial (facet) joint pain. Anesthesiology 106:591-614.

Collins DL, Neelin P, Peters TM, Evans AC (1994) Automatic 3D intersubject registration of MR volumetric data in standardized Talairach space. J Comput Assist Tomogr 18:192-205.

Collins DL, Holmes CJ, Peters TM, Evans AC (1995) Automatic 3-D modelbased neuroanatomical segmentation. Hum Brain Mapp 3:190-208. 
Dick B, Eccleston C, Crombez G (2002) Attentional functioning in fibromyalgia, rheumatoid arthritis, and musculoskeletal pain patients. Arthritis Rheum 47:639-644.

Dick BD, Connolly JF, McGrath PJ, Finley GA, Stroink G, Houlihan ME, Clark AJ (2003) The disruptive effect of chronic pain on mismatch negativity. Clin Neurophysiol 114:1497-1506.

Dickerson BC, Fenstermacher E, Salat DH, Wolk DA, Maguire RP, Desikan R, Pacheco J, Quinn BT, Van der Kouwe A, Greve DN, Blacker D, Albert MS, Killiany RJ, Fischl B (2008) Detection of cortical thickness correlates of cognitive performance: reliability across MRI scan sessions, scanners, and field strengths. Neuroimage 39:10-18.

Eccleston C (1995) Chronic pain and distraction: an experimental investigation into the role of sustained and shifting attention in the processing of chronic persistent pain. Behav Res Ther 33:391-405.

Fahim C, Yoon U, Das S, Lyttelton O, Chen J, Arnaoutelis R, Rouleau G, Sandor P, Frey K, Brandner C, Evans AC (2010) Somatosensory-motor bodily representation cortical thinning in Tourette: effects of tic severity, age and gender. Cortex 46:750-760.

Fairbank JC, Couper J, Davies JB, O’Brien JP (1980) The Oswestry low back pain disability questionnaire. Physiotherapy 66:271-273.

Fierro B, De Tommaso M, Giglia F, Giglia G, Palermo A, Brighina F (2010) Repetitive transcranial magnetic stimulation (rTMS) of the dorsolateral prefrontal cortex (DLPFC) during capsaicin-induced pain: modulatory effects on motor cortex excitability. Exp Brain Res 203:31-38.

Fox MD, Snyder AZ, Vincent JL, Corbetta M, Van Essen DC, Raichle ME (2005) The human brain is intrinsically organized into dynamic, anticorrelated functional networks. Proc Natl Acad Sci U S A 102:9673-9678.

Geha PY, Baliki MN, Harden RN, Bauer WR, Parrish TB, Apkarian AV (2008) The brain in chronic CRPS pain: abnormal gray-white matter interactions in emotional and autonomic regions. Neuron 60:570-581.

Giesecke T, Gracely RH, Grant MA, Nachemson A, Petzke F, Williams DA, Clauw DJ (2004) Evidence of augmented central pain processing in idiopathic chronic low back pain. Arthritis Rheum 50:613-623.

Graff-Guerrero A, González-Olvera J, Fresán A, Gómez-Martín D, MéndezNúñez JC, Pellicer F (2005) Repetitive transcranial magnetic stimulation of dorsolateral prefrontal cortex increases tolerance to human experimental pain. Brain Res Cogn Brain Res 25:153-160.

Gwilym SE, Fillipini N, Douaud G, Carr AJ, Tracey I (2010) Thalamic atrophy associated with painful osteoarthritis of the hip is reversible after arthroplasty; a longitudinal voxel-based-morphometric study. Arthritis Rheum. Advance online publication. doi:10.1002/art.27585.

Hadjikhani N, Joseph RM, Snyder J, Tager-Flusberg H (2007) Abnormal activation of the social brain during face perception in autism. Hum Brain Mapp 28:441-449.

Hardy SG, Haigler HJ (1985) Prefrontal influences upon the midbrain: a possible route for pain modulation. Brain Res 339:285-293.

Harman K, Ruyak P (2005) Working through the pain: a controlled study of the impact of persistent pain on performing a computer task. Clin J Pain 21:216-222.

Hoffman GA, Harrington A, Fields HL (2005) Pain and the placebo: what we have learned. Perspect Biol Med 48:248-265.

Hsu MC, Harris RE, Sundgren PC, Welsh RC, Fernandes CR, Clauw DJ, Williams DA (2009) No consistent difference in gray matter volume between individuals with fibromyalgia and age-matched healthy subjects when controlling for affective disorder. Pain 143:262-267.

Kabani N, Le Goualher G, MacDonald D, Evans AC (2001) Measurement of cortical thickness using an automated 3-D algorithm: a validation study. Neuroimage 13:375-380.

Kewman DG, Vaishampayan N, Zald D, Han B (1991) Cognitive impairment in musculoskeletal pain patients. Int J Psychiatry Med 21:253-262.

Kim JS, Singh V, Lee JK, Lerch J, Ad-Dab'bagh Y, MacDonald D, Lee JM, Kim SI, Evans AC (2005) Automated 3-D extraction and evaluation of the inner and outer cortical surfaces using a Laplacian map and partial volume effect classification. Neuroimage 27:210-221.

Kobayashi Y, Kurata J, Sekiguchi M, Kokubun M, Akaishizawa T, Chiba Y, Konno S, Kikuchi S (2009) Augmented cerebral activation by lumbar mechanical stimulus in chronic low back pain patients: an fMRI study. Spine 34:2431-2436.

Krishnan KR, France RD, Pelton S, McCann UD, Davidson J, Urban BJ (1985) Chronic pain and depression. I. Classification of depression in chronic low back pain patients. Pain 22:279-287.

Krummenacher P, Candia V, Folkers G, Schedlowski M, Schönbächler G
(2010) Prefrontal cortex modulates placebo analgesia. Pain 148:368-374

Kuchinad A, Schweinhardt P, Seminowicz DA, Wood PB, Chizh BA, Bushnell MC (2007) Accelerated brain gray matter loss in fibromyalgia patients: premature aging of the brain? J Neurosci 27:4004-4007.

Kulkarni B, Bentley DE, Elliott R, Youell P, Watson A, Derbyshire SWG, Frackowiak RSJ, Friston KJ, Jones AKP (2005) Attention to pain localization and unpleasantness discriminates the functions of the medial and lateral pain systems. Eur J Neurosci 21:3133-3142.

Lee DM, Pendleton N, Tajar A, O’Neill TW, O'Connor DB, Bartfai G, Boonen S, Casanueva FF, Finn JD, Forti G, Giwercman A, Han TS, Huhtaniemi IT, Kula K, Lean MEJ, Punab M, Silman AJ, Vanderschueren D, Moseley CM, $\mathrm{Wu}$ FCW, et al. (2010) Chronic widespread pain is associated with slower cognitive processing speed in middle-aged and older European men. Pain 151:30-36.

Lloyd D, Findlay G, Roberts N, Nurmikko T (2008) Differences in low back pain behavior are reflected in the cerebral response to tactile stimulation of the lower back. Spine 33:1372-1377.

Lorenz J, Beck H, Bromm B (1997) Cognitive performance, mood and experimental pain before and during morphine-induced analgesia in patients with chronic non-malignant pain. Pain 73:369-375.

Lorenz J, Minoshima S, Casey KL (2003) Keeping pain out of mind: the role of the dorsolateral prefrontal cortex in pain modulation. Brain 126:1079-1091.

Lutz J, Jäger L, de Quervain D, Krauseneck T, Padberg F, Wichnalek M, Beyer A, Stahl R, Zirngibl B, Morhard D, Reiser M, Schelling G (2008) White and gray matter abnormalities in the brain of patients with fibromyalgia: a diffusion-tensor and volumetric imaging study. Arthritis Rheum 58:3960-3969.

Lyttelton O, Boucher M, Robbins S, Evans A (2007) An unbiased iterative group registration template for cortical surface analysis. Neuroimage 34:1535-1544.

MacDonald D, Kabani N, Avis D, Evans AC (2000) Automated 3-D extraction of inner and outer surfaces of cerebral cortex from MRI. Neuroimage $12: 340-356$.

May A (2008) Chronic pain may change the structure of the brain. Pain 137:7-15.

Mayberg HS (2009) Targeted electrode-based modulation of neural circuits for depression. J Clin Invest 119:717-725.

McNair DM, Lorr M, Droppleman LF (1971) Profile of Mood States. San Diego: Educational and Industrial Testing Service.

Melzack R (1987) The Short-Form McGill Pain Questionnaire. Pain 30:191-197.

Nahmias F, Debes C, de Andrade DC, Mhalla A, Bouhassira D (2009) Diffuse analgesic effects of unilateral repetitive transcranial magnetic stimulation (rTMS) in healthy volunteers. Pain 147:224-232.

Obermann M, Nebel K, Schumann C, Holle D, Gizewski ER, Maschke M, Goadsby PJ, Diener HC, Katsarava Z (2009) Gray matter changes related to chronic posttraumatic headache. Neurology 73:978-983.

O'Reardon JP, Solvason HB, Janicak PG, Sampson S, Isenberg KE, Nahas Z, McDonald WM, Avery D, Fitzgerald PB, Loo C, Demitrack MA, George MS, Sackeim HA (2007) Efficacy and safety of transcranial magnetic stimulation in the acute treatment of major depression: a multisite randomized controlled trial. Biol Psychiatry 62:1208-1216.

Oshiro Y, Quevedo AS, McHaffie JG, Kraft RA, Coghill RC (2009) Brain mechanisms supporting discrimination of sensory features of pain: a new model. J Neurosci 29:14924-14931.

Pariente J, White P, Frackowiak RS, Lewith G (2005) Expectancy and belief modulate the neuronal substrates of pain treated by acupuncture. Neuroimage 25:1161-1167.

Park DC, Glass JM, Minear M, Crofford LJ (2001) Cognitive function in fibromyalgia patients. Arthritis Rheum 44:2125-2133.

Rapoport J, Jacobs P, Bell NR, Klarenbach S (2004) Refining the measurement of the economic burden of chronic diseases in Canada. Chronic Dis Can 25:13-21.

Reid P, Pridmore S (2001) Improvement in chronic pain with transcranial magnetic stimulation. Aust N Z J Psychiatry 35:252.

Rodriguez-Raecke R, Niemeier A, Ihle K, Ruether W, May A (2009) Brain gray matter decrease in chronic pain is the consequence and not the cause of pain. J Neurosci 29:13746-13750.

Schmidt-Wilcke T, Leinisch E, Straube A, Kämpfe N, Draganski B, Diener 
HC, Bogdahn U, May A (2005) Gray matter decrease in patients with chronic tension type headache. Neurology 65:1483-1486.

Schmidt-Wilcke T, Leinisch E, Gänssbauer S, Draganski B, Bogdahn U, Altmeppen J, May A (2006) Affective components and intensity of pain correlate with structural differences in gray matter in chronic back pain patients. Pain 125:89-97.

Schweinhardt P, Kuchinad A, Pukall CF, Bushnell MC (2008) Increased gray matter density in young women with chronic vulvar pain. Pain 140:411-419.

Seeley D (1990) Selected nonpharmacological therapies for chronic pain: the therapeutic use of the placebo effect. J Am Acad Nurse Pract 2:10-16.

Seminowicz DA, Davis KD (2006) Cortical responses to pain in healthy individuals depends on pain catastrophizing. Pain 120:297-306.

Seminowicz DA, Davis KD (2007a) Interactions of pain intensity and cognitive load: the brain stays on task. Cereb Cortex 17:1412-1422.

Seminowicz DA, Davis KD (2007b) Pain enhances functional connectivity of a brain network evoked by performance of a cognitive task. J Neurophysiol 97:3651-3659.

Seminowicz DA, Laferriere AL, Millecamps M, Yu JS, Coderre TJ, Bushnell MC (2009) MRI structural brain changes associated with sensory and emotional function in a rat model of long-term neuropathic pain. Neuroimage 47:1007-1014.

Seminowicz DA, Labus JS, Bueller JA, Tillisch K, Naliboff BD, Bushnell MC, Mayer EA (2010) Regional gray matter density changes in brains of patients with irritable bowel syndrome. Gastroenterology 139:48-57.e2.

Sled JG, Zijdenbos AP, Evans AC (1998) A nonparametric method for automatic correction of intensity nonuniformity in MRI data. IEEE Trans Med Imaging 17:87-97.

Sowell ER, Mattson SN, Kan E, Thompson PM, Riley EP, Toga AW (2008) Abnormal cortical thickness and brain-behavior correlation patterns in individuals with heavy prenatal alcohol exposure. Cereb Cortex 18:136-144.

Tagliazucchi E, Balenzuela P, Fraiman D, Chialvo DR (2010) Brain resting state is disrupted in chronic back pain patients. Neurosci Lett 485:26-31.

Teutsch S, Herken W, Bingel U, Schoell E, May A (2008) Changes in brain gray matter due to repetitive painful stimulation. Neuroimage 42:845-849.

Tohka J, Zijdenbos A, Evans A (2004) Fast and robust parameter estimation for statistical partial volume models in brain MRI. Neuroimage 23:84-97.

Tu CH, Niddam DM, Chao HT, Chen LF, Chen YS, Wu YT, Yeh TC, Lirng JF, Hsieh JC (2010) Brain morphological changes associated with cyclic menstrual pain. Pain 150:462-468.

Veldhuijzen DS, Kenemans JL, van Wijck AJ, Olivier B, Kalkman CJ, Volkerts ER (2006) Processing capacity in chronic pain patients: a visual eventrelated potentials study. Pain 121:60-68.

Vogt BA (2005) Pain and emotion interactions in subregions of the cingulate gyrus. Nat Rev Neurosci 6:533-544

Wager TD, Rilling JK, Smith EE, Sokolik A, Casey KL, Davidson RJ, Kosslyn SM, Rose RM, Cohen JD (2004) Placebo-induced changes in fMRI in the anticipation and experience of pain. Science 303:1162-1167.

Wiech K, Kalisch R, Weiskopf N, Pleger B, Stephan KE, Dolan RJ (2006) Anterolateral prefrontal cortex mediates the analgesic effect of expected and perceived control over pain. J Neurosci 26:11501-11509.

Wood PB, Glabus MF, Simpson R, Patterson JC 2nd (2009) Changes in gray matter density in fibromyalgia: correlation with dopamine metabolism. J Pain 10:609-618.

Worsley KJ, Marrett S, Neelin P, Vandal AC, Friston KJ, Evans AC (1996) A unified statistical approach for determining significant signals in images of cerebral activation. Hum Brain Mapp 4:58-73.

Zijdenbos AP, Forghani R, Evans AC (2002) Automatic "pipeline" analysis of 3-D MRI data for clinical trials: application to multiple sclerosis. IEEE Trans Med Imaging 21:1280-1291. 